\title{
Mineração
}

\section{Ensaios estáticos e cinéticos para a prevenção da geração de drenagem ácida de minas da mineração de carvão com escória de aciaria}

\author{
(Static and kinetic tests to prevent the generation of acid mine \\ drainage from coal mining with steel slag)
}

\author{
Luciana Angelita Machado \\ Mestre em Engenharia, PPGEM/UFRGS \\ E-mail: lucianapoa@gmail.com \\ Ivo André Homrich Schneider \\ Professor, Dr., DEMET/PPGEM/UFRGS \\ E-mail:ivo.andre@ufrgs.br
}

\section{Resumo}

A Drenagem Ácida de Mina (DAM) é proveniente da oxidação natural de materiais sulfetados quando em contato com o ar e com a água. Esse problema atinge, em alto grau, a mineração de carvão. Uma das tecnologias de prevenção da geração da DAM consiste no método de aditivos alcalinos. Assim, o objetivo do presente trabalho foi avaliar, em estudos de laboratório, o controle da DAM pela mistura de um rejeito de carvão com uma escória do setor siderúrgico. O trabalho incluiu a coleta de uma amostra de rejeito de carvão de uma mineração de carvão e de uma amostra de escória de uma usina siderúrgica semi-integrada, ambas situadas no Estado do Rio Grande do Sul. Determinaram-se o potencial de geração de acidez e o potencial de neutralização dos materiais pelo método de contabilização de ácidos e bases. Após, realizaram-se ensaios cinéticos em células úmidas pelo Método ASTM D 5744-96. Os resultados demonstram que o rejeito de carvão gera DAM. Contudo os problemas ambientais podem ser em grande parte resolvidos pela mistura do rejeito com a escória em uma proporção de 4,8:1. Os ensaios cinéticos demonstram que, nessa condição, ocorre um aumento do $\mathrm{pH}$ e uma redução na liberação de acidez, metais e sulfatos na água lixiviada. Desta forma, foi demonstrado que a disposição conjunta de escória de aciaria com rejeito de carvão é uma alternativa viável para o controle da geração de DAM em minerações de carvão.

Palavra-chave: Drenagem ácida de mina, escória, aditivos alcalinos.

\begin{abstract}
The Acid Mine Drainage (AMD) is the result of the natural oxidation of sulphide minerals when exposed to the combined action of water and oxygen. One of the technologies to prevent the AMD consists in the alkaline additive method. Thus, the aim of this work was to study, at laboratory scale, the DAM control by blending coal waste with a metallurgical slag. A coal-tailing sample was collected from a coal mine and the slag was obtained from a semi-integrated steel plant, both located in Rio Grande do Sul State, Brazil. Static tests were carried out by the acid-base account method to determine the balance between the acid producing and acid consuming (neutralizing) mineral components of the sample. Later, kinetic tests were conducted in humidity cells, following the ASTM D 5744-96 method. The results showed that the coal tailing generates DAM. However, the environmental problems can be minimized mixing the coal waste with the metallurgical slag in a 4,8:1 proportion. The kinetic experiments proved that, in this condition, the lixiviate presents a higher $\mathrm{pH}$ and lower concentration of acidity, metals and sulphate. Finally, it is possible to conclude the blending slag in coal tailing deposits can be a viable alternative for DAM control in coal mining.
\end{abstract}

Keywords: Acid drainage of mine, slag, alkaline additives. 


\section{Introdução}

A Drenagem Ácida de Minas (DAM) é um problema ambiental importante enfrentado pelo setor de mineração. Resulta de reações químicas de sulfetos metálicos na presença de ar e água. Esse tipo de poluição é comum em áreas de mineração de carvão, uma vez que a pirita e a marcassita (ambos $\mathrm{FeS}_{2}$, porém em formas cristalinas distintas) são encontradas nas jazidas de carvão. Os poluentes da DAM afetam a qualidade da água, baixando o $\mathrm{pH}$, reduzindo a alcalinidade natural, aumentando a dureza total e acrescendo quantidades indesejáveis de ferro, alumínio, manganês, sulfatos e, eventualmente, outros metais pesados. Locais geradores de DAM permanecem ativos por décadas e até mesmo por séculos após a sua produção (Kontopoulos, 1998)

Os métodos de controle da DAM podem ser classificados em métodos preventivos, de controle da migração e remediação (Kontopoulos, 1998). O método preventivo de aditivos alcalinos baseia-se na mistura de materiais alcalinos com rochas geradoras de DAM. O método é considerado simples e de baixo custo, mas não tem sido aplicado na mineração de carvão do Brasil. O calcário $\left(\mathrm{CaCO}_{3}\right)$ é o material tradicionalmente aplicado. Porém vários setores industriais geram resíduos alcalinos que não encontram aplicação. Entre os resíduos que poderiam ser usados como aditivos alcalinos para a prevenção da geração de DAM estão as escórias siderúrgicas, cinzas da queima do carvão em termoelétricas e resíduos da construção civil (Skousen et al., 1998; Lilge et al., 2005).

Nesse contexto, os ensaios estáticos e cinéticos têm por finalidade avaliar o potencial de geração da DAM por um determinado material. Os testes estáticos são rápidos e possibilitam a aplicação de critérios específicos que permitem a classificação das amostras segundo seu potencial de geração de acidez e potencial de neutralização. Ainda, permitem quantificar a relação entre resíduos alcalinos e rejeitos de mineração para que ocorra a neutralização. Os ensaios cinéticos auxiliam no entendimento da geração de DAM ao longo do tempo, bem como podem prever a qualidade da água lixiviada (EPA, 1994).

Deve-se ressaltar que testes estáticos e cinéticos têm sido aplicados somente recentemente como ferramenta para o controle da DAM pelas mineradoras de carvão no Brasil (Indústria Carbonífera Rio Deserto, 2004; Lilge et al., 2005). Dessa forma, o presente trabalho visa a contribuir para o estabelecimento de metodologia e caracterização de alguns materiais existentes no Estado do Rio Grande do Sul (RS), propondo-se a avaliar possibilidades de misturas entre rejeitos de carvão e resíduos alcalinos, de forma a evitar a geração da DAM.

\section{Material e métodos}

\subsection{Rejeito de carvão e escória de aciaria}

A amostra de rejeito de carvão foi proveniente do beneficiamento, por jigagem, do carvão da Mina do Recreio, localizada no município de Butiá-RS. O material alcalino estudado foi a escória gerada no refino secundário, proveniente do forno-panela da Gerdau Siderúrgica Riograndense, uma usina semi-integrada de produção de aço, localizada em Sapucaia-RS.

\subsection{Análise imediata de carvão}

A análise imediata do rejeito de carvão considerou o poder calorífico superior, o teor de cinzas, o teor de matéria volátil, o enxofre total, pirítico, sulfático e orgânico e a análise elementar de carbono, hidrogênio e nitrogênio. $O$ poder calorífico superior foi determinado em bomba calorimétrica, seguindo a metodologia ASTM D-5865 (ASTM, 2004). A análise de cinzas foi realizada pela queima de 1,0 grama de carvão, por 1 hora a $800^{\circ} \mathrm{C}$, em mufla, conforme NBR 8289 (ABNT, 1983a). A matéria volátil foi determinada pela queima de 1,0 grama de amostra, por 5 minutos a $950^{\circ} \mathrm{C}$, em mufla, seguindo a norma NBR 8290 (ABNT, 1983b). O enxofre total foi analisado via instrumental, pelo equipamento Leco SC 457. As formas de enxofre sulfático e pirítico foram determinadas por procedimentos titulométricos, normatizados pela ISO 157 (1996). A forma orgânica do enxofre foi determinada pela subtração do enxofre sulfático e pirítico do teor de enxofre total. Os valores obtidos foram corrigidos em relação ao teor de umidade, medida pela secagem de $1,0 \mathrm{~g}$ de amostra, por 1 hora a $110^{\circ} \mathrm{C}$, conforme a norma NBR 8293 (ABNT, 1983c).

\subsection{Testes estáticos}

O teste estático empregado foi o de contabilização de ácidos e bases (ABA). Foram realizados os testes ABA tradicional e ABA modificado. Ambos tem por objetivo determinar o balanço entre a produção e o consumo de acidez pelos componentes minerais de uma amostra. Por esses testes, determinam-se o potencial de produção de acidez (AP) e o potencial de neutralização (NP) (Sobek et al., 1978; EPA, 1994).

A partir desses parâmetros, podese calcular:

- Potencial de neutralização líquido $(\mathrm{NNP})=\mathrm{NP}-\mathrm{AP}$

- Razão do potencial de neutralização $(\mathrm{NPR})=\mathrm{NP} / \mathrm{AP}$

onde o AP, NP e NNP são, geralmente, expressos em $\mathrm{kg} \mathrm{CaCO}_{3} / \mathrm{t}$ de amostra.

A determinação do potencial de acidez (AP) pelo método ABA tradicional foi realizada pela análise de enxofre total, via instrumental no equipamento Leco CS 457. A medida do AP pelo método ABA modificado foi realizada pela análise de enxofre pirítico, via úmida. Estequiometricamente, um mol de $\mathrm{CaCO}_{3}$ é requerido por mol de $\mathrm{S}$ :

$\mathrm{AP}\left(\mathrm{kg} \mathrm{CaCO}_{3} / \mathrm{t}\right)=(1000 / 32) \times$ peso $\% \mathrm{~S}$

A determinação do potencial de neutralização (NP) pelo método ABA tradicional foi realizada pelo ataque da amostra com ácido clorídrico aquecido a $90^{\circ} \mathrm{C}$, por 1 hora, para consumir os minerais neutralizantes, seguido de titulação com $\mathrm{NaOH}$ até $\mathrm{pH} 7,0$. A medida do NP pelo 
método ABA modificado foi realizada pelo ataque da amostra com ácido clorídrico, a temperatura ambiente, por 24 horas, seguido de titulação com $\mathrm{NaOH}$ até $\mathrm{pH}$ 8,3. O cálculo do NP foi realizado pela seguinte equação:

$\mathrm{NP}\left(\mathrm{kg} \mathrm{CaCO}_{3} / \mathrm{t}\right)=(\mathrm{HCl}$ cons., g/g de amostra $) \times(50 / 36,5) \times 1000$

Os critérios ABA para identificação do potencial de geração de acidez dos materiais são (NNP e NPR):

- Valores de NNP menores que -20 indicam que haverá a formação de ácido.

- Valores de NNP maiores que + 20 indicam que não haverá a formação de ácido.

- Valores de NNP entre -20 e + 20 indicam que é difícil prever a formação ou não de ácido.

- Valores do NPR menores 1:1 indicam a provável geração de DAM.

- Valores de NPR entre 1:1 e 2:1 indicam a possível geração de DAM.

- Valores de NPR entre 2:1 e 4:1 indicam que a DAM não é esperada.

- Valores de NPR maiores que 4:1 indicam que não será gerada a DAM.

\subsection{Ensaios cinéticos}

Os estudos cinéticos foram realizados pelo método de células úmidas, conforme procedimento ASTM D 5744 (ASTM, 1996). O teste consistiu em colocar uma amostra de 1000 gramas com granulometria inferior a $6,3 \mathrm{~mm}$ em um frasco fechado por onde pode ser injetado e retirado ar. Inicialmente, submeteuse a amostra a uma lixiviação com $1000 \mathrm{~mL}$ de água destilada por um dia e coletouse o lixiviado para análise. Após, submeteram-se as amostras por três dias ao ar seco, três dias ao ar úmido e um dia para percolação de água. Esse ciclo se repetiu por todo o período de teste aplicado, que foi de 20 semanas.

Nos experimentos, uma célula foi preenchida com rejeito de carvão, outra com escória e outra com uma mistura dos materiais em uma proporção de 4,8:1. Assim, os materiais inseridos, em cada célula, e sua respectiva quantia, foram:

- 1000 g de rejeito de carvão da Mina do Recreio(RC).

- 1000 g de escória da Siderúrgica Riograndense (ESC).

- Mistura de 830 g do rejeito de carvão com 170 g de escória.

As amostras de águas lixiviadas das células úmidas foram analisadas em relação aos seguintes parâmetros de qualidade de água: $\mathrm{pH}$, potencial redox, acidez, alcalinidade total, ferro, alumínio, manganês, zinco, sulfato e condutividade. As análises foram realizadas, semanalmente, seguindo os procedimentos do "Standard Methods for the Examination of Water and Wastewater" (APHA, 2005).

\section{Resultados e discussão}

A Tabela 1 apresenta a análise imediata do rejeito de carvão. Pode-se observar que o rejeito apresenta $68,7 \%$ de cinzas. O teor de enxofre total é de 4,8\% e de enxofre pirítico é de 3,2\%. Esses dados são representativos dos rejeitos de carvão gerados no beneficiamento por jigagem no Estado do Rio Grande do Sul. (Féris et al., 2001).

Os resultados dos ensaios estáticos estão discriminados na Tabela 2 . Para o rejeito de carvão, os valores do potencial de neutralização líquido (NNP) e razão do potencial de neutralização (NPR) obtidos pelo método ABA tradicional foram $-148,8 \mathrm{kgCaCO}_{3} / \mathrm{t}$ e 0,008 , respectivamente. Os valores obtidos pelo método ABA modificado foram $-100,0 \mathrm{kgCaCO}_{3} / \mathrm{t}$ e 0,0. Assim, os valores de NNP e NPR indicam que o material é gerador de DAM na presença de ar e água. Comparando esses dados com estudos realizados com rejeito de carvão produzido no Estado de Santa Catarina (SC), os valores do NNP do rejeito de carvão do Rio Grande do Sul são inferiores. Isso se deve ao fato de que os rejeitos de carvão de Santa Catarina apresentam um teor de enxofre mais elevado. Valores do NNP do rejeito primário de jigagem de Santa Catarina podem chegar à faixa de $-300 \mathrm{a}-500 \mathrm{kgCaCO}_{3} / \mathrm{t}$ (Lilge et al., 2005).

A escória de aciaria apresentou-se como um material promissor a ser empregado como aditivo alcalino. Obteve-se

Tabela 1 - Análise imediata do rejeito de carvão.

\begin{tabular}{c|c}
\hline Propriedade & Valores \\
\hline Poder Calorífico Superior (kcal/kg) & 1380 \\
\hline Enxofre Total (\%) & 4,8 \\
\hline Enxofre Pirítico (\%) & 3,2 \\
\hline Enxofre Sulfático (\%) & 1,4 \\
\hline Enxofre Orgânico (\%) & 0,2 \\
\hline Matéria Volátil (\%) & 17,9 \\
\hline Cinzas (\%) & 68,7 \\
\hline $\mathrm{C}(\%)$ & 14,9 \\
\hline $\mathrm{H}(\%)$ & 1,6 \\
\hline $\mathrm{N}(\%)$ & 0,3 \\
\hline
\end{tabular}

REM: R. Esc. Minas, Ouro Preto, 61(3): 329-335, jul. set. 2008 
um NNP de $444,1 \mathrm{kgCaCO}_{3} / \mathrm{t}$ pelo método ABA tradicional e um NNP de $484,4 \mathrm{kgCaCO}_{3} / \mathrm{t}$ pelo $\mathrm{ABA}$ modificado. Os valores estão coerentes com dados apresentados por Skousen et al. (1998), que descrevem que o NP da escórias pode variar de 400 a $950 \mathrm{kgCaCO}_{3} / \mathrm{t}$. Essa alta alcalinidade é conferida pelos teores elevados de óxido de cálcio $(\mathrm{CaO})$ e de óxido de magnésio (MgO). Com base nesses dados, calculou-se a proporção entre os materiais para que a geração de acidez e alcalinidade ficasse equilibrada. Pelos dados de NNP, obtidos no método ABA tradicional, a proporção de materiais para o equilíbrio é de, aproximadamente, $3: 1$, enquanto que pelo método ABA modificado, essa proporção passa para 4,8:1.

As Figuras de 1 a 10 apresentam os resultados dos ensaios cinéticos. Os resultado foram conduzidos com uma célula contendo rejeito de carvão (RC), outra contendo escória (ESC) e outra com uma mistura dos dois materiais (RC+ESC). Nesse caso, optou-se por realizar o experimento em uma proporção de 4,8:1 (RC:ESC), uma vez que, por dados de literatura, o método ABA tradicional tende a superestimar a formação de DAM, enquanto o método ABA modificado permite determinações mais próximas da realidade (EPA, 1994; Kontopoulos, 1998).

Para o rejeito de carvão, pode-se observar que o $\mathrm{pH}$ da água lixiviada foi baixo no decorrer das 20 semanas, variando entre 2,6 e 1,3. O potencial redox, na semana 0 (zero), foi de $490 \mathrm{mV}$. Após se estabilizou na entre 649 e $711 \mathrm{mV}$, demonstrando uma condição altamente oxidante que favorece a degradação de sulfetos. As concentrações de ferro e sulfato, dois produtos diretos da oxidação da pirita, apresentaram um comportamento similar. Na semana 0 (zero), a concentração de ferro no lixiviado foi alta, mostrando que a pirita já estava parcialmente oxidada (decorrente de operações de beneficiamento, armazenamento e transporte). Entre as semanas 1 e 10, os valores se mantiveram mais baixos, voltando a subir a partir da semana 11 . O mesmo comportamento ocorreu para o sulfato. Os demais elementos metálicos, lixiviados a partir da matéria mineral, como o alumínio, manganês e zinco, tiveram um comportamento distinto. Apresentam valores mais altos nas primeiras lixiviações, decrescendo com o decorrer das semanas. As maiores concentrações foram observadas para o alumínio, seguido do manganês e zinco. Como conseqüência do baixo $\mathrm{pH}$ e da presença de metais e íons sulfato dissolvidos, a água lixiviada apresentou uma alta acidez e condutividade.

A água lixiviada da célula contendo somente escória apresentou valores de $\mathrm{pH}$ iniciais em torno de 12,0, chegando, no final do ensaio, com valores de 9,7 (com exceção das duas últimas semanas, quando o $\mathrm{pH}$ voltou a aumentar para 11,9 e 11,8 , respectivamente). A alcalinidade na semana 0 foi de $785 \mathrm{mg} / \mathrm{kgCa}-$ $\mathrm{CO}_{3}$. Nas semanas seguintes, este valor diminuiu, chegando a $20 \mathrm{mg} / \mathrm{kgCaCO}$. Em relação aos metais ( $\mathrm{Fe}, \mathrm{Al}, \mathrm{Mn}$ e $\mathrm{Zn})$, a concentração no lixiviado, em todo o experimento, foi próxima a zero. A liberação de sulfatos também foi praticamente nula.

Nas alíquotas obtidas da célula com o rejeito de carvão misturado com escória, o pH ficou na faixa de 5,0 e 4,0 nas dez primeiras semanas, baixando para valores entre 4,0 e 3,0 nas semanas seguintes. Os valores de $\mathrm{pH}$, na faixa ácida, podem ser explicados pelo fato de que a acidez liberada pelo rejeito de carvão é superior (entre 10 e 100 vezes) à alcalinidade liberada pela escória. A redução gradativa no $\mathrm{pH}$ é decorrente da diminuição de liberação de alcalinidade pela escória no decorrer do experimento. O potencial redox do lixiviado variou de 306 a $573 \mathrm{mV}$. Esses dados indicam que a presença da escória diminui o potencial de oxidação, provavelmente reduzindo as condições de oxidação da pirita. Esses dados estão de acordo com conclusões de Capanema e Ciminelli (2003), que observaram que maiores valores de potencial redox favorecem a oxidação de materiais sulfetados, com a decorrente diminuição do $\mathrm{pH}$ da água lixiviada. Em relação aos metais, somente a água de lixiviação na semana 0 (zero) apresentou uma concentração mais elevada. A partir de então, a lixiviação dos metais foi bastante baixa. Esse fato está associado ao $\mathrm{pH}$ mais elevado do meio, que inibe a oxidação da pirita, reduz a solubilidade dos metais e favorece os processos de adsorção de compostos metálicos na matéria mineral (Simmons et al., 2002). Os teores de sulfato também são bastante baixos, demonstrando que a oxidação da pirita foi bastante reduzida.

Esses dados podem ser confirmados pelo balanço de massa (Tabela 3). Os dados demonstram que a célula que continha somente rejeito de carvão apresentou maior perda em massa e maior perda de enxofre do que a célula que continha a mistura dos materiais. A perda em massa da célula contendo somente rejeito de carvão foi de $8,4 \%$, enquanto que na célula em que houve a mistura dos materiais foi de somente $2,8 \%$. A lixiviação do elemento enxofre na célula contendo somente rejeito de carvão foi de $50,4 \%$, enquanto que na célula em que houve a mistura de materiais foi de $20,5 \%$.

Assim, os resultados obtidos confirmam que a mistura de rejeitos de carvão com escória de aciaria reduz a taxa de oxidação da pirita, diminuindo a concentração de poluentes na água de percolação. Esses resultados demonstram que a técnica de aditivos alcalinos, com o uso de escórias, pode ser uma tecnologia viável e de baixo custo para o controle da drenagem ácida na mineração de carvão no Rio Grande do Sul. Deve-se considerar que a escória do forno-panela é atualmente destinada a aterros.

\section{Conclusões}

O rejeito de carvão da Mina do Recreio, com $4,8 \%$ de enxofre total e $3,2 \%$ de enxofre pirítico, tem potencial de geração de acidez. O ensaio cinético em célula úmida demonstrou que esse material gera DAM, fato evidenciado pelo $\mathrm{pH}$ menor que 2,6, alta acidez e elevadas concentrações de metais ( $\mathrm{Fe}, \mathrm{Al}, \mathrm{Mn}$ e $\mathrm{Zn}$ ) e sulfato. A escória do forno-panela apresenta um alto potencial de neutralização, O ensaio cinético realizado somente com a escória propiciou um lixiviado 
Luciana Angelita Machado al.

Tabela 2 - Resultados de ensaios estáticos para o rejeito de carvão e a escória.

\begin{tabular}{c|c|c|c|c|c}
\hline ABA tradicional & $\% \mathbf{S}$ Total & $\mathbf{A P}\left(\mathrm{kgCaCO}_{3} / \mathbf{t}\right)$ & $\mathbf{N P}\left(\mathrm{kgCaCO}_{3} / \mathbf{t}\right)$ & $\mathbf{N N P}$ & NPR \\
\hline Rejeito de carvão & 4,8 & 150 & 1,2 & $-148,8$ & 0,008 \\
\hline Escória & 0,1 & 3,1 & 447,2 & 444,1 & 144,2 \\
\hline ABA modificado & $\%$ S Pirítico & AP $(\mathbf{k g C a C O} / \mathbf{t})$ & $\mathbf{N P}(\mathbf{k g C a C O} / \mathbf{t})$ & $\mathbf{N N P}$ & $\mathbf{N P R}$ \\
\hline Rejeito de carvão & 3,2 & 100 & 0 & -100 & 0 \\
\hline Escória & 0 & 0 & 484,4 & 484,4 & - \\
\hline
\end{tabular}

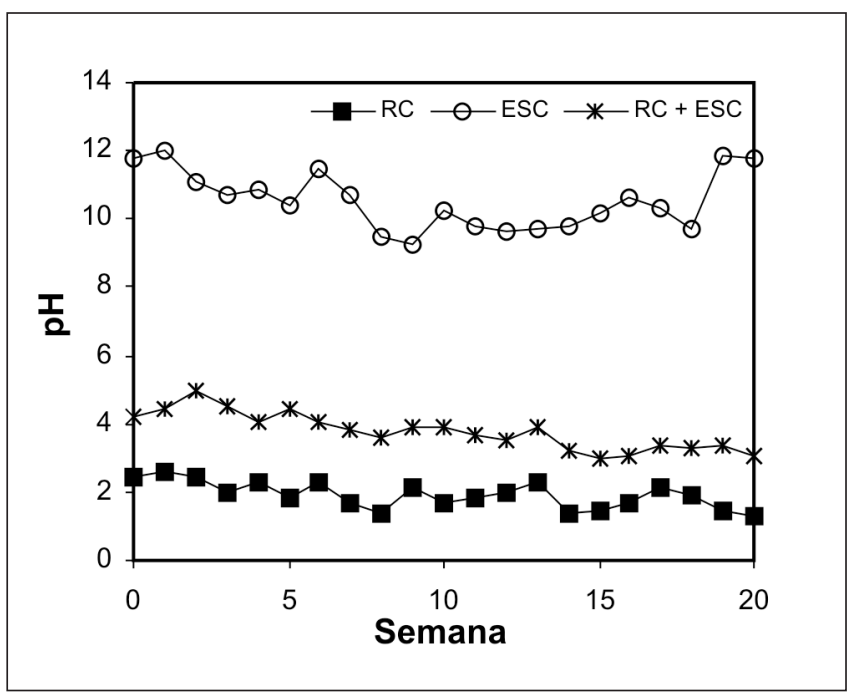

Figura $1-\mathrm{pH}$ da água lixiviada nos ensaios cinéticos no $\mathrm{RC}$, ESC e RC + ESC.

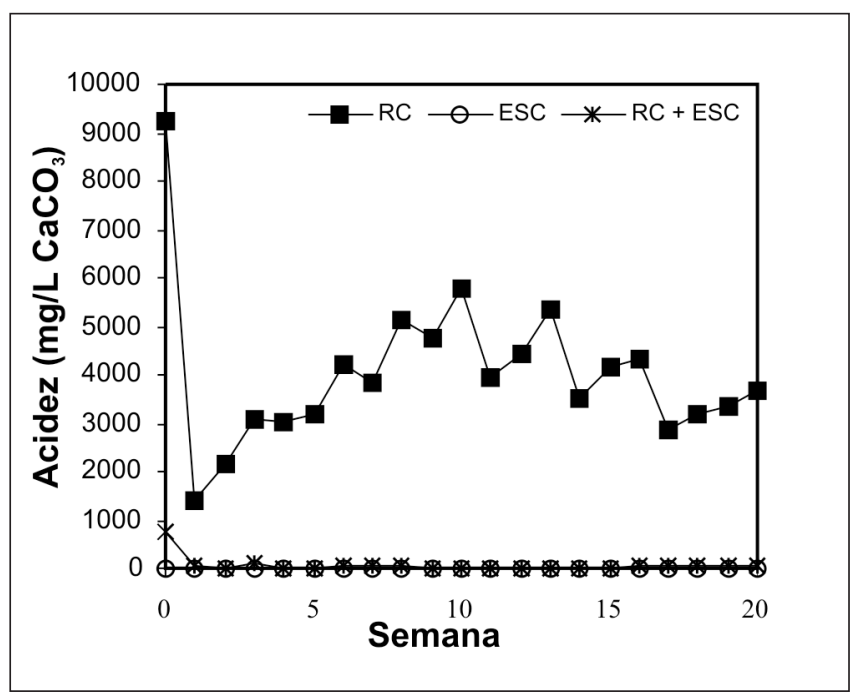

Figura 3 - Acidez da água lixiviada nos ensaios cinéticos no RC, ESC e RC + ESC.

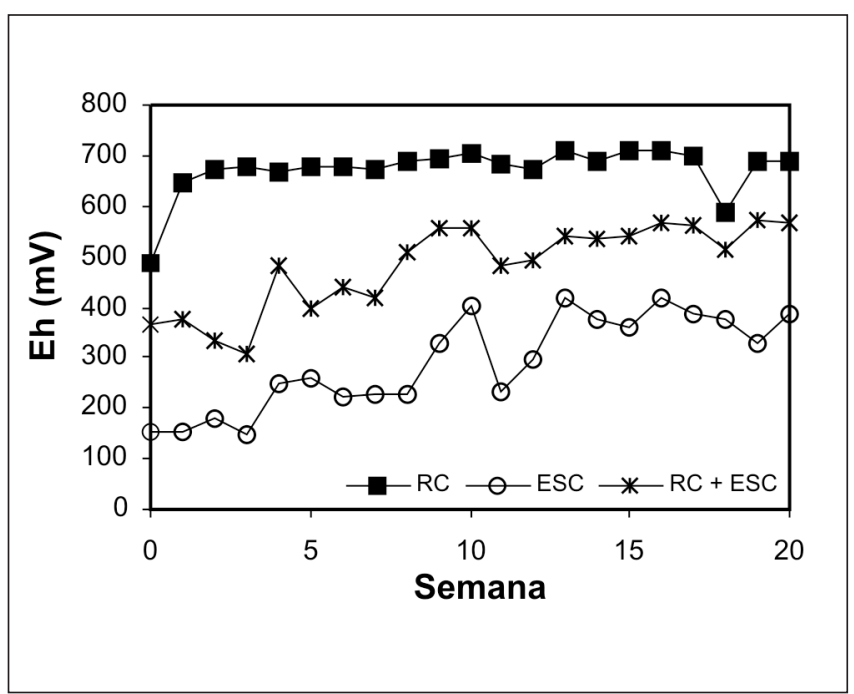

Figura 2 - Potencial redox da água lixiviada nos ensaios cinéticos no RC, ESC e RC + ESC.

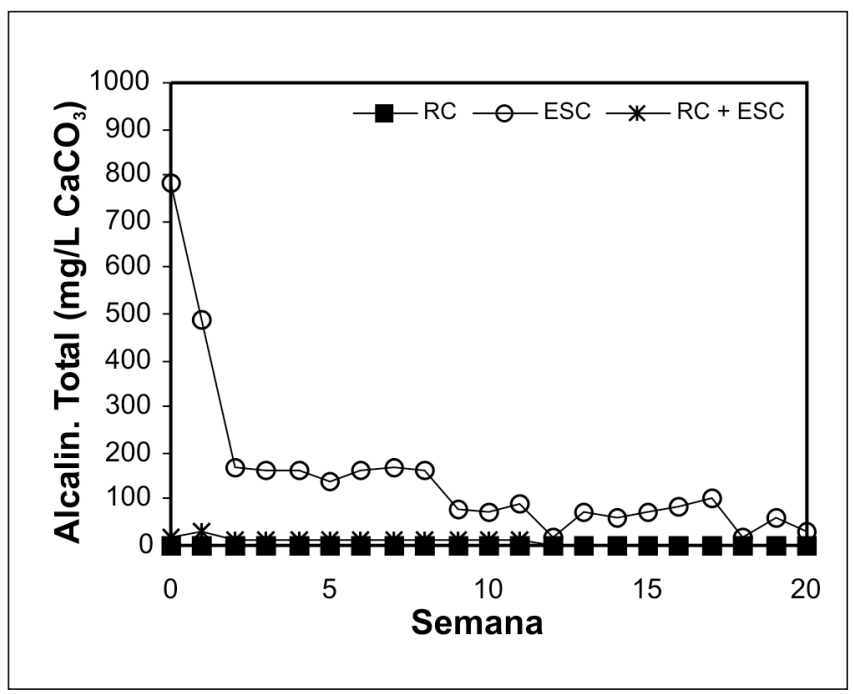

Figura 4 - Alcalinidade da água lixiviada nos ensaios cinéticos no RC, ESC e RC + ESC. 


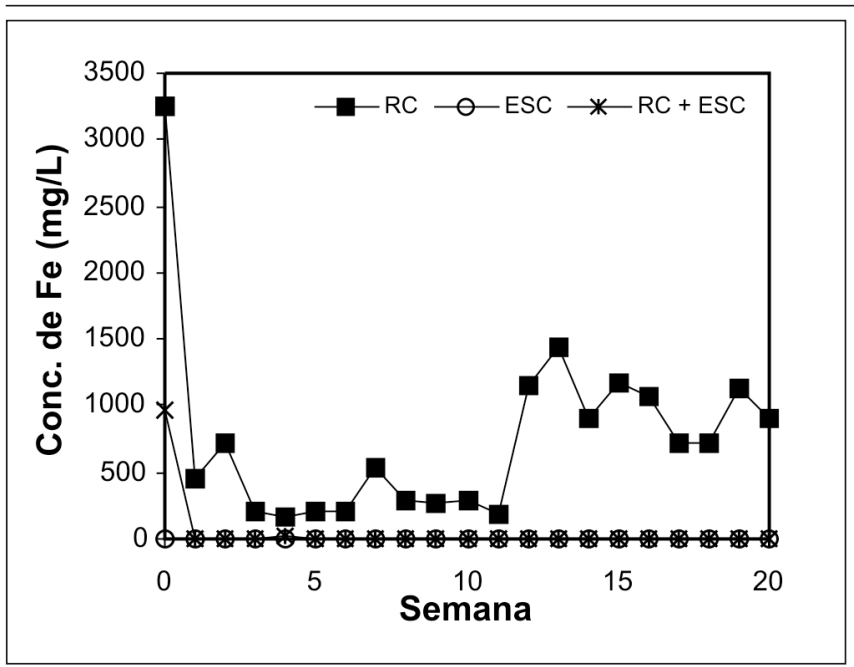

Figura 5 - Concentração de ferro na água lixiviada nos ensaios cinéticos no RC, ESC e RC + ESC.

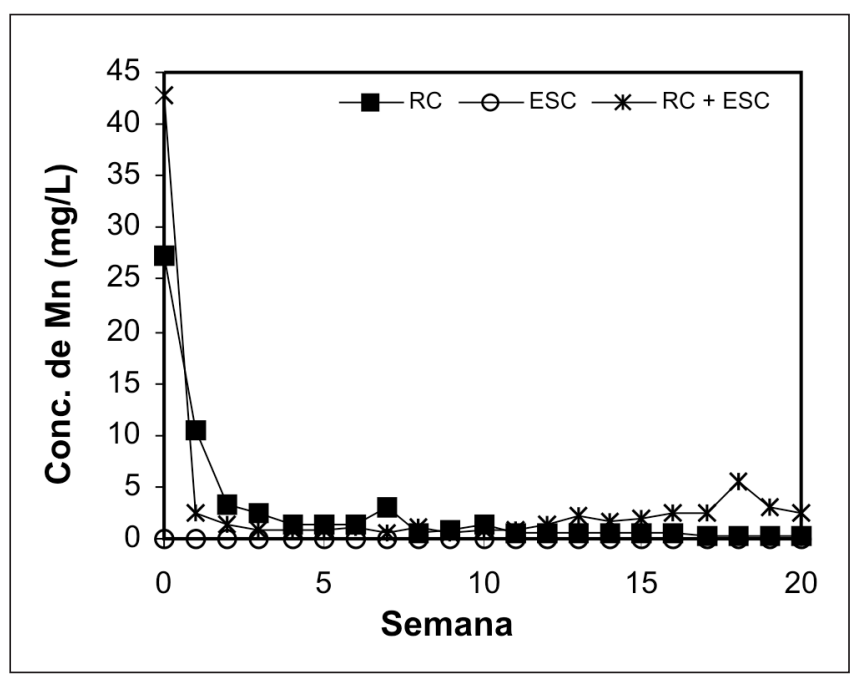

Figura 7 - Concentração de manganês na água lixiviada nos ensaios cinéticos no RC, ESC e RC + ESC.

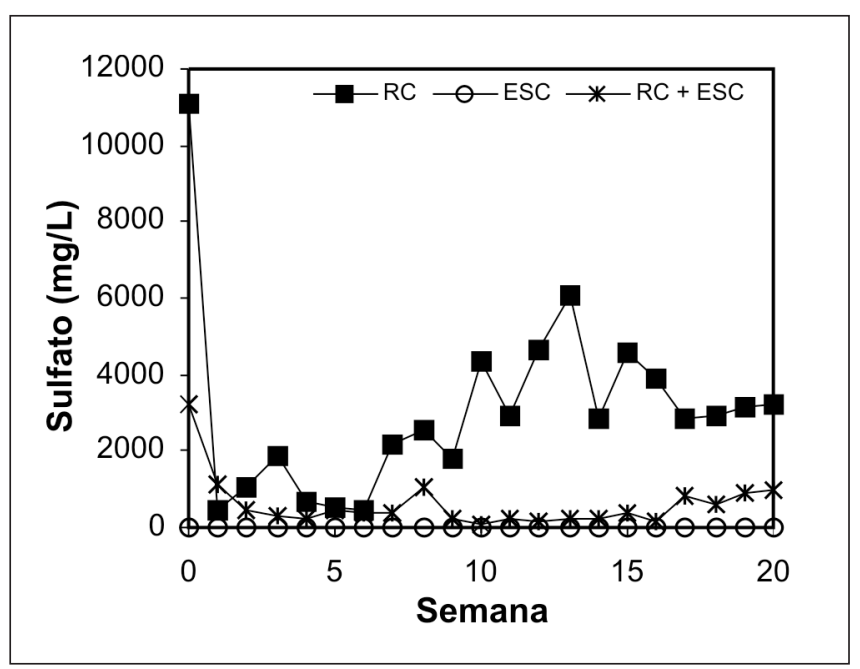

Figura 9 - Concentração de sulfatos na água lixiviada nos ensaios cinéticos no RC, ESC e RC + ESC.

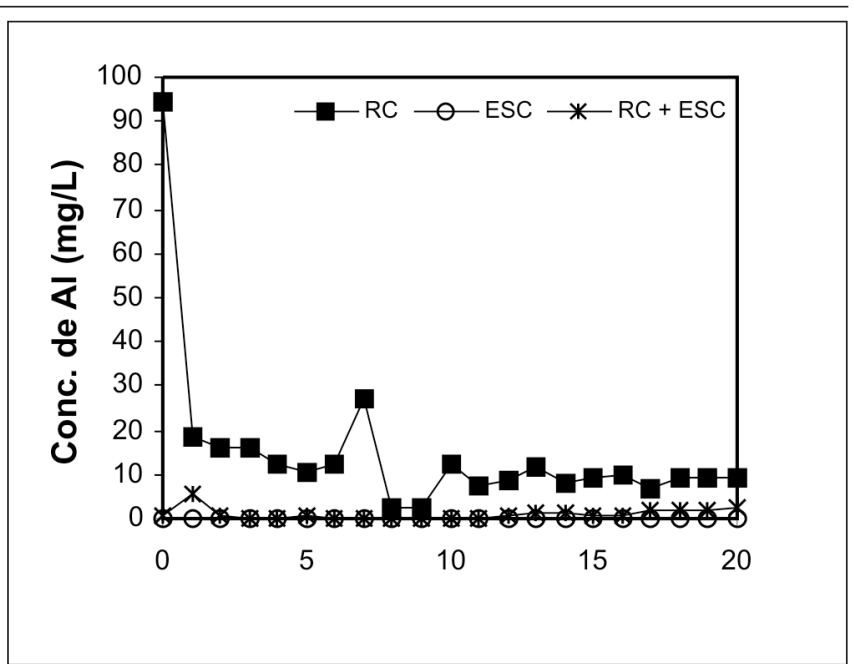

Figura 6 - Concentração de alumínio na água lixiviada nos ensaios cinéticos no RC, ESC e RC + ESC.

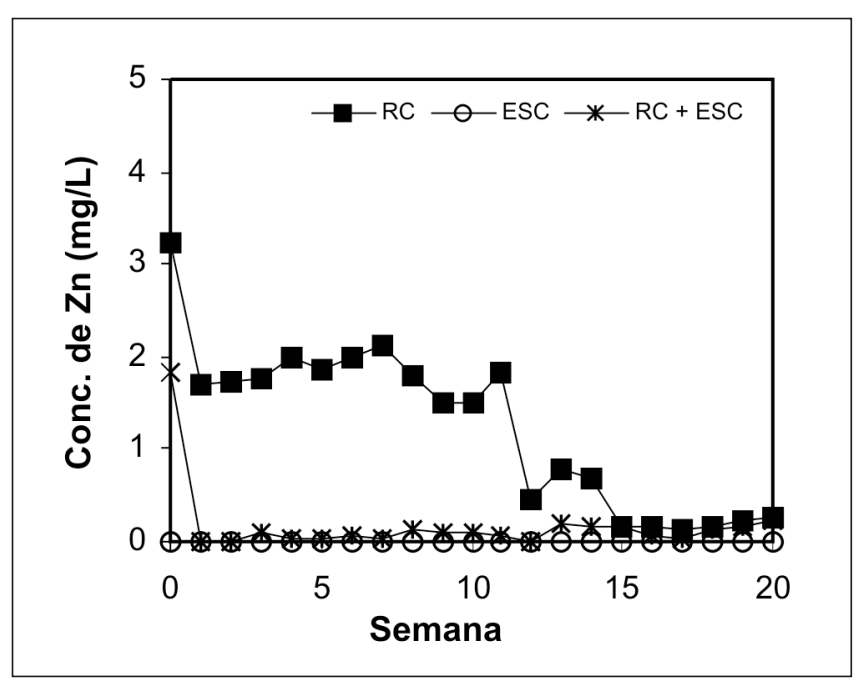

Figura 8 - Concentração de zinco na água lixiviada nos ensaios cinéticos no RC, ESC e RC + ESC.

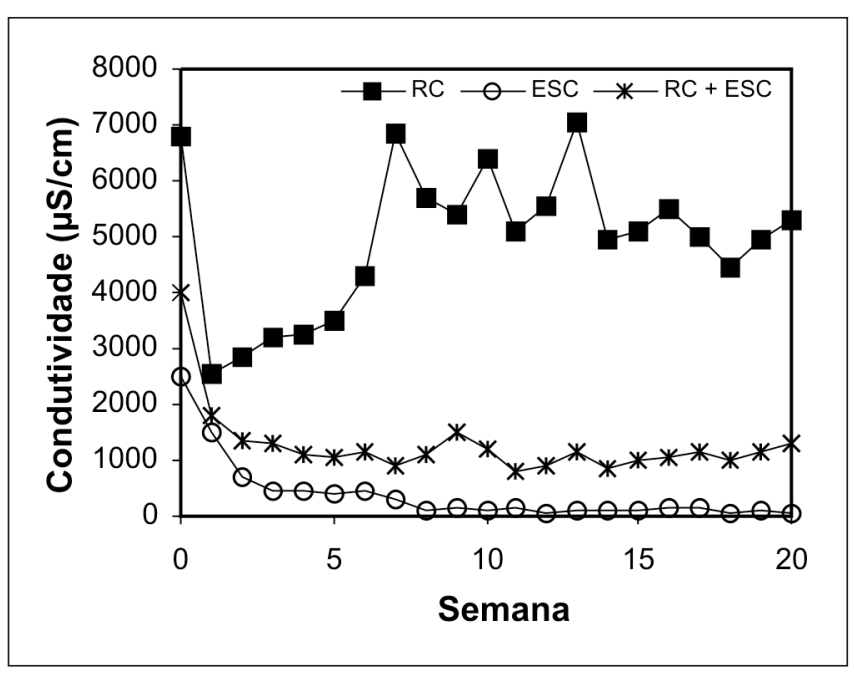

Figura 10 - Condutividade da água lixiviada nos ensaios cinéticos no RC, ESC e RC + ESC. 
Luciana Angelita Machado al.

Tabela 3 - Balanço de massa do enxofre nas células úmidas.

\begin{tabular}{|c|c|c|c|c|c|c|c|c|}
\hline & \multicolumn{3}{|c|}{ Semana 0} & \multicolumn{3}{|c|}{ Semana 20} & \multirow{2}{*}{$\begin{array}{c}\text { Massa lix. } \\
(\%)\end{array}$} & \multirow{2}{*}{$\begin{array}{c}S_{\text {total }} \text { lix } \\
(\%)\end{array}$} \\
\hline Amostras & $\begin{array}{l}\text { Massa } \\
\text { total(g) }\end{array}$ & $\begin{array}{c}\text { Teor } \\
\mathbf{S}_{\text {total }}(\%)\end{array}$ & $\begin{array}{l}\text { Massa } \\
S_{\text {total }}(g)\end{array}$ & $\begin{array}{c}\text { Massa } \\
\text { total(g) }\end{array}$ & $\begin{array}{c}\text { Teor } \\
\mathbf{S}_{\text {total }}(\%)\end{array}$ & $\begin{array}{c}\text { Massa } \\
\mathrm{S}_{\text {total }}(\mathrm{g})\end{array}$ & & \\
\hline C & 1000 & 4,8 & 48,0 & 916 & 2,6 & 23,8 & 8,4 & 50,4 \\
\hline ESC & 1000 & 0,1 & 1,0 & 974 & 0,1 & 0,97 & 2,6 & 3,0 \\
\hline $\mathrm{RC}+\mathrm{ESC}$ & 1000 & 3,9 & 39,0 & 972 & 3,2 & 31,1 & 2,8 & 20,2 \\
\hline
\end{tabular}

com pH entre 9,7 e 12,0, moderada alcalinidade e concentrações baixas de metais e sulfatos. A mistura do rejeito de carvão e escória permitiu a minimização da geração da DAM, obtendo-se um lixiviado com $\mathrm{pH}$ entre 3,0 e 5,0, baixa acidez e concentrações reduzidas de metais (Fe, Al, Mn e Zn) e sulfatos. Assim, demonstrou-se que a disposição conjunta de escória e rejeito de carvão é uma alternativa viável para minimizar a taxa de oxidação da pirita, reduzindo os efeitos da DAM nas áreas de influência das minerações de carvão.

\section{Agradecimentos}

Os autores agradecem ao $\mathrm{CNPq}$ e CAPES pelo apoio financeiro para o desenvolvimento do presente trabalho. Também são gratos a Copelmi Mineração e ao Grupo Gerdau pelo fornecimento das amostras dos materiais.

\section{Referências bibliográficas}

AMERICAN PUBLIC HEALTH ASSOCIATION - APHA. Standard methods for the examination of water and wastewater. 21. Ed. Washington D.C: APHA-AWWAWEF, 2005. 1134p.

AMERICAN SOCIETY FOR TESTING AND MATERIAL - ASTM. ASTM D 5744: standard test method for accelerated weathering of solid materials using a modified humidity cell. $1996,13 \mathrm{p}$.
AMERICAN SOCIETY FOR TESTING AND MATERIAL - ASTM. ASTM D 5865: standard test method for gross calorific value of coal and coke. 2004, 9p.

ASSOCIAÇÃO BRASILEIRA DE NORMAS TÉCNICAS - ABNT. NBR 8289: determinação do teor de cinza. Rio de Janeiro: 1983a. 4p.

ASSOCIAÇÃO BRASILEIRA DE NORMAS TÉCNICAS - ABNT. NBR 8290: determinação do teor de matéria volátil. Rio de Janeiro: 1983b. 3p.

ASSOCIAÇÃO BRASILEIRA DE NORMAS TÉCNICAS - ABNT. NBR 8293: determinação de umidade. Rio de Janeiro: 1983c. 6p.

CAPANEMA, L.X.L., CIMINELLI, V.S.T. An investigation of acid rock drainage (ARD) occurrence in a gold mine located in a Southeastern Brazil region. REMRevista Escola de Minas, v. 56, n.3, p.201-206, 2003.

ENVIRONMENTAL PROTECTION AGENCY - EPA. EPA 530-R-94-036. Acid Mine Drainage Prediction. 1994. 48p. (Technical Document).

FÉRIS, L.A., FLORES, J.A., SCHNEIDER, I.A.H., RUBIO, J. Sorption of metals on a coal beneficiation tailing material. I: characterization an mechanisms involved. Coal Preparation, v.21, p.235-248, 2001.

INDÚSTRIA CARBONÍFERA RIO DESERTO LTDA. Análise do potencial de acidificação e de neutralização em rejeitos do beneficiamento do carvão mineral da região carbonífera. Relatório Técnico Empresas Rio Deserto, Criciúma, SC, 2004. 58p. (Relatório Técnico).

INTERNATIONAL ORGANIZATION FOR STANDARDIZATION - ISO. ISO 157: hard coal: determination of forms of sulfur. 1996. 15p.

KONTOPOULOS, A. Acid mine drainage control. In: CASTRO, S.H. et alii. (Eds.). Effluent treatment in the mining industry. Chile: University of Concepciòn, 1998. p. 57-118.

LILGE, D.S, HAHN, M.B., SCHNEIDER, I.A.H., SILVA, G.S.R., GOMES, K.M.S., GOMES, C.J.B. Ensaios estáticos e cinéticos na previsão da drenagem ácida de minas na mineração de carvão no sul do Estado de Santa Catarina, RS - Brasil. In: ENCONTRO NACIONAL DE TRATAMENTO DE MINÉRIOS E METALURGIA EXTRATIVA, 21. Anais... Natal, 2005. CD ROM.

SIMMONS J., ZIEMKIEWICZ, P., BLACK, D.C. Use of steel slag leach beds for the treatment of acid mine drainage. Mine Water and the Environment. v.21, p.9199, 2002.

SKOUSEN, J., ROSE, A., GEIDEL, G., FOREMAN, J., EVANS, R., HELLIER, W. $\boldsymbol{A}$ handbook of technologies for avoidance and remediation of acid mine drainage. West Virginia University and the National Mine Land Reclamation Center, 1998. 132p.

SOBEK, A.A., SCHULlER, W.A., FREEMAN, J.R., SMITH, R.M. Field and laboratory methods applicable to overburden and minesoils, EPA 600/2-78054, 1978.203p.

Artigo recebido em 27/06/2007 e aprovado em 01/03/2008. 